\title{
Hydrodynamics and Mass Transfer Performance of Annulus-Rising Airlift Reactor - The Effect of Reactor Scale
}

\author{
Mei Han, Arto Laari, and Tuomas Koiranen
}

\begin{abstract}
Hydrodynamic and mass transfer characteristics of an annulus-rising airlift reactor (AR_ALR) were investigated with experimental and CFD simulation methods. An Eulerian model with two bubble phases was developed to simulate the AR_ALR in three circulation flow regimes. 3D steady state CFD simulations were performed under different gas superficial velocities $\left(U_{g}\right)$. Good agreements on gas holdup and volumetric mass transfer coefficient were obtained over the range of the studied $U_{g}$. The simulated averaged liquid velocities in AR_ALR with different scales were compared and accounted for the influence of reactor scale on gas holdup. The three flow regimes in AR_ALR were captured well and are similar to those observed in experiments. The developed CFD model can be used to predict the hydrodynamics and mass transfer in AR_ALRs with different scales.
\end{abstract}

Index Terms-Annulus-rising airlift reactor, CFD, mass transfer, scale-up effect.

\section{INTRODUCTION}

Airlift loop reactors (ALRs) have received more and more attention in chemical, petrochemical and biochemical industries. They are used in fermentation, waste water purification, hydrogenation and exhaust-gas treatment [1], [2] ALRs have some advantages over bubble columns such as enhanced mixing, mass and heat transfer, and suspension of particles with low energy consumption. The mild and constant shear environment in ALRs, contrary to mixing tanks, is preferable for bioprocesses with fragile particles [3].

ALRs usually are composed of a riser with a gas feed, and a downcomer where the liquid phase flows downwards. An enlarged expansion, called gas separator, is often placed on the top of the column in order to achieve good separation of gas and liquid phases. Generally, two types of ALRs, an internal-loop airlift reactor (IL-ALR) and an external-loop airlift reactor (EL-ALR), are classified according to the arrangement of the riser and the downcomer. For IL-ALR, two operating modes can be used which are the gas-feeding in the draft tube (center-rising airlift reactor, CR_ALR) and the gas feeding in the annulus (annulus-rising airlift reactor, AR_ALR) modes.

A large number of studies on CR_ALRs have been reported and great achievements have been obtained with experimental [4]-[8] or simulation [9]-[14] methods. However, studies on AR_ALRs are quite scarce [15]-[18] although Koide et al. [17],[18] have shown in their experimental studies that

Manuscript received October 15, 2015; revised August 25, 2016.

The authors are with Lappeenranta University of Technology (LUT), Finland (e-mail: mei.han@lut.fi, arto.laari@lut.fi, tuomas.koiranen@lut.fi).
AR_ALRs have in fact higher gas holdups and mass transfer rates than CR_ALRs, especially for liquid phase systems which have frothing properties. The anti-frothing ability of the AR_ALRs is higher than CR_ALRs due to much more bubbles being entrained into the downcomer. Moreover, most of the studies, typically in bioprocesses, have been performed in bench-scale (1 - 10 L) ALRs [15] and are limited to the specified aeration rates [2]. The yield of desired products may be lower than expected even in pilot-scale applications [19] due to the effects of the reactor scale, aeration and agitation. It is therefore necessary to investigate the effect of aeration and scale on hydrodynamics and mass transfer in AR_ALR so that the performance of the reactor would satisfy the process needs as well as possible.

The aim of this work was to investigate the effects of aeration and reactor scale on hydrodynamics and mass transfer performance of AR_ALRs in order to promote their industrial applications. This study on a laboratory AR_ALR was, therefore, conducted with experiments and CFD simulations for different gas superficial velocities. An Eulerian model with two bubble phases was developed to simulate the hydrodynamics and mass transfer performance of the AR_ALR. Furthermore, the effect of reactor scale was predicted and compared with experimental studies from the literature.

\section{EXPERIMENTS}

A schematic diagram of the experimental setup used in the studies is shown in Fig. 1.

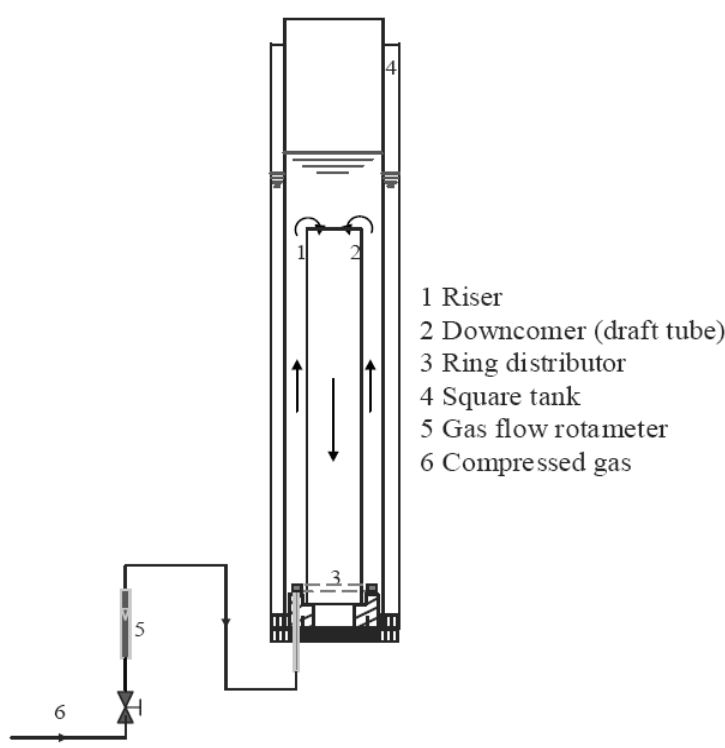

Fig. 1. Schematic diagram of the experimental setup. 
The laboratory-scale AR_ALR consists of two cylinders made of acrylic resin with a wall thickness of $0.005 \mathrm{~m}$. A plastic ring gas distributor with a diameter of $0.12 \mathrm{~m}$ was installed in the annulus between the outer and the inner cylinders at $0.07 \mathrm{~m}$ above the bottom. There are 36 holes of $0.5 \mathrm{~mm}$ diameter distributed equidistantly at the top of the ring gas distributor. Table I gives the dimensions of the AR_ALR in details.

TABLE I: THE DIMENSIONS OF THE AR_ALR

\begin{tabular}{ccc}
\hline \hline Dimension, $\mathrm{m}$ & Riser & Downcomer \\
\hline Diameter & 0.15 & 0.10 \\
\hline Height & 1.20 & 0.60 \\
\hline \hline
\end{tabular}

Compressed air was used as the dispersed phase and it was operated in once-through mode. Tap water was the continuous phase and it was used as a batch. The unaerated liquid height was $0.8 \mathrm{~m}$. All the experiments were carried out at room temperature and atmospheric pressure. The operating gas superficial velocity, $U_{g}$, was calculated based on the cross-sectional area of the riser and was in the range 0.41 $2.55 \mathrm{~cm} / \mathrm{s}$, as listed in Table II.

The overall gas holdup, $\left\langle a_{g, \text { overall }}\right\rangle$, in the column was measured by the height expansion method and calculated by Equation (1).

$$
\left\langle a_{g, \text { overall }}\right\rangle=\left(H_{m}-H_{l}\right) / H_{m}
$$

where $H_{m}$ and $H_{l}$ are the height of the mixture after aeration and the height of the liquid before aeration, respectively.

Digital imaging method was used to evaluate the bubble size at the height of $0.5 \mathrm{~m}$ above the base of the AR_ALR. 1000 images were acquired and analyzed with image analysis software PORA [20]. More than $10^{5}$ bubbles were detected for each $U_{g}$, which was found to be enough for the measured bubble size value to converge to a constant value.

The volumetric mass transfer coefficient, $k_{L} a$, was determined by using a dynamic oxygen absorption method. The dissolved oxygen concentration was monitored and recorded using a MARVET BASIC 2000 Dissolved Oxygen Meter (Elke Sensor OÜ) with the oxygen sensor located at 0.6 $m$ above the gas distributor. Nitrogen was first sparged into the AR_ALR until the dissolved oxygen concentration was close to zero and steady-state hydrodynamic conditions were reached. Then, nitrogen flow was shut down and compressed air feed was started. A pressure valve and a digital mass-flow controller were used to keep the nitrogen and the compressed air feeds at constant level in order not to interrupt the flow fields. Sufficient time was given in each experimental run to strip out the dissolved nitrogen and to saturate the liquid phase with oxygen to the maximum level. To calculate the volumetric oxygen mass transfer coefficient, it is assumed that the liquid phase is perfectly mixed and that oxygen depletion from the gas bubbles is negligible. The rate of oxygen dissolution in the liquid phase can be described by Equation (2),

$$
d C_{L} / d t=k_{L} \alpha_{L}\left(C^{*}-C_{L}\right)
$$

where $k_{L} a_{L}$ is the volumetric mass transfer coefficient per unit volume of liquid in the AR_ALR. $C_{L}$ is the dissolved-oxygen concentration in the liquid and $C^{*}$ is the oxygen saturation concentration.

The sensor of the dissolved oxygen meter has a time constant, $k_{\text {sensor }}$, corresponding to the delay in recording due to the inherently finite response time. The oxygen concentration value indicated by the sensor, $C_{\text {sensor }}$ satisfies [21],

$$
d C_{\text {sensor }} / d t=k_{\text {sensor }}\left(C_{L}-C_{\text {sensor }}\right)
$$

where $C_{L}$ is the concentration of dissolved oxygen. In the experiments to determine the value of $\mathrm{k}_{\text {sensor }}$, two beakers with water saturated with nitrogen and oxygen were used, respectively. A value of $0.0625 \mathrm{~s}^{-1}$ was obtained for the $\mathrm{k}_{\mathrm{sensor}}$ by making a regression of the $C_{\text {sensor }} / C_{L}$ values versus time. Analytical solution of (2) along with the sensor dynamics given by (3), yields [22],

$$
\begin{aligned}
C_{\text {sensor }} / C^{*}=1- & k_{\text {sensor }} e^{-k_{L} a_{L} t} /\left(k_{\text {sensor }}-k_{L} a_{L}\right) \\
& +k_{L} a_{L} e^{-k_{\text {sensor }} t} /\left(k_{\text {sensor }}-k_{L} a_{L}\right)
\end{aligned}
$$

The volumetric mass transfer coefficient per volume of the reactor can then be determined by using (5):

$$
k_{L} a=k_{L} a_{L}\left(1-\left\langle a_{g, \text { overall }}\right\rangle\right)
$$

\section{SIMULATION}

\section{A. Governing Equations}

An Eulerian model with two bubble phases was developed to simulate the hydrodynamics and mass transfer of AR_ALRs. This model includes two bubble phases as the dispersed phase and one liquid continuous phase. Each bubble phase has a uniform size but a different bubble diameter value. The large bubble phase (g1) and the small bubble phase (g2) were defined according to measured bubble sizes. The diameter varies from 0.005 to $0.008 \mathrm{~m}$ for the large bubble phase and from 0.001 to $0.003 \mathrm{~m}$ for the small one corresponding to $U_{g}$. The exact diameter values for both bubble phases are listed in Table II according to $U_{g}$.

TABLE II: BUBBLE SIZES CORRESPONDING TO GAS SUPERFICIAL VELOCITIES

\begin{tabular}{ccc}
$\begin{array}{c}\text { Gas superficial velocity, } \\
\mathrm{cm} / \mathrm{s}\end{array}$ & $\begin{array}{c}\text { Bubble size of g1, } \\
\mathrm{mm}\end{array}$ & $\begin{array}{c}\text { Bubble size of g2, } \\
\mathrm{mm}\end{array}$ \\
\hline 0.41 & 5.0 & 3.0 \\
\hline 0.65 & 5.0 & 2.0 \\
\hline 1.18 & 6.0 & 1.5 \\
\hline 1.74 & 7.0 & 1.5 \\
\hline 2.55 & 8.0 & 1.0 \\
\hline
\end{tabular}

Interaction between $\mathrm{g} 1$ and $\mathrm{g} 2$ was not considered and no bubble coalescence or breakage was involved. The momentum transfer $\left(\boldsymbol{M}_{\boldsymbol{k}}\right)$ between the gas phases and the liquid phase was formulated by taking the $\operatorname{drag}\left(\boldsymbol{F}_{\boldsymbol{D}, \boldsymbol{k}}\right)$, lift $\left(\boldsymbol{F}_{\boldsymbol{L}}\right.$, $\left.{ }_{k}\right)$, wall lubrication $\left(\boldsymbol{F}_{W, k}\right)$ and turbulent dispersion forces $\left(\boldsymbol{F}_{T}\right.$, ${ }_{k}$ ) into account [13]. The turbulence of the liquid phase was resolved by the dispersed standard $k-\varepsilon$ turbulent model. The 
governing equations are listed in Table III in detail.

TABLE III: The DEVELoPed THREE-PHASE EULERIAN MODEL

\begin{tabular}{|c|c|}
\hline Item & Model \\
\hline Continuity & $\nabla \cdot\left(\alpha_{k} \rho_{k} \mathbf{u}_{k}\right)=0, k=l, g 1, g 2$ \\
\hline \multirow{6}{*}{ Momentum } & $\nabla \cdot\left(\alpha_{l} \rho_{l} \mathbf{u}_{l} \mathbf{u}_{l}\right)=-\alpha_{l} \nabla P^{\prime}+\nabla \cdot\left(\alpha_{l} \mu_{e f f, l}\left(\nabla \mathbf{u}_{l}+\nabla \mathbf{u}_{l}^{T}\right)\right)$ \\
\hline & $+\rho_{l} \alpha_{l} \mathbf{g}+M_{l}$ \\
\hline & $\nabla \cdot\left(\alpha_{g i} \rho_{g i} \mathbf{u}_{g i} \mathbf{u}_{g i}\right)=-\alpha_{g i} \nabla P^{\prime}+\nabla \cdot\left(\alpha_{g i} \mu_{e f f, g i}\left(\nabla \mathbf{u}_{g i}+\nabla \mathbf{u}_{g i}^{T}\right)\right)$ \\
\hline & $+\rho_{g i} \alpha_{g i} \mathbf{g}+M_{g i}$ \\
\hline & $i=g 1, g 2$ \\
\hline & $M_{l}=-\left(M_{g 1}+M_{g 2}\right)=\sum_{i=1}^{2} \mathbf{F}_{D, g i}+\sum_{i=1}^{2} \mathbf{F}_{L, g i}+\sum_{i=1}^{2} \mathbf{F}_{W, g i}+\sum_{i=1}^{2} \mathbf{F}_{T, g i}$ \\
\hline \multirow{5}{*}{$F_{D, g i}$} & $\mathbf{F}_{D, g i}=3 / 4 \alpha_{g i} \alpha_{l} \rho_{l} C_{D, g i} / d_{g i}\left|\mathbf{u}_{g i}-\mathbf{u}_{l}\right|\left(\mathbf{u}_{g i}-\mathbf{u}_{l}\right)$ \\
\hline & $C_{D, g 1}=\max \left[\min \left(24 / \operatorname{Re}_{r, g 1}\left(1+0.15 \mathrm{Re}_{r, 81}^{0.687}\right), 72 / \operatorname{Re}_{r, g 1}\right)\right.$, \\
\hline & $\left.8 / 3\left(E o_{g 1} /\left(E o_{g 1}+4\right)\right)\right]$ \\
\hline & $C_{0}=\left\{24\left(1+0.15 \mathrm{Re}_{r, 82}^{0.687}\right) / \operatorname{Re}_{r, g 2}, \operatorname{Re}_{r, g 2} \leq 1000\right.$ \\
\hline & $\mathrm{C}_{D, g 2}= \begin{cases}0.44, & \mathrm{Re}_{r, g 2}>1000\end{cases}$ \\
\hline \multirow[t]{5}{*}{$F_{L, g i}$} & $\mathbf{F}_{L, g i}=-C_{L, g i} \alpha_{g i} \rho_{l}\left(\mathbf{u}_{g i}-\mathbf{u}_{l}\right) \times\left(\nabla \times \mathbf{u}_{l}\right)$ \\
\hline & $\left(\min \left(0.288 \tanh n\left(\operatorname{Re}_{r, g i}\right), f\left(E o_{g i}\right)\right), E o_{g i} \leq 4\right.$ \\
\hline & $C_{L, g i}=\left\{f\left(E o_{g i}\right), \quad 4<E o_{g i} \leq 10\right.$ \\
\hline & $\mid-0.27, \quad 10<E o_{g i}$ \\
\hline & $f\left(E o_{g i}\right)=0.00105 E o_{s i}{ }^{3}-0.0159 E o_{s i}^{\prime}-0.0204 E o_{s i t}^{\prime}+0.474$ \\
\hline$F_{T, g i}$ & $\mathbf{F}_{T, g i}=-\rho_{l} C_{T} \nabla \alpha_{l}, C_{T}=0.1$ \\
\hline$F_{W, g i}$ & $\begin{aligned} \mathbf{F}_{W, g i}= & \alpha_{g i} \rho_{l}\left(\mathbf{u}_{\text {sip } p, g i}-\left(\mathbf{u}_{s i p, g i} n_{w}\right) n_{w}\right) / d_{g i} \\
& \times \max \left(C_{W 1}+C_{W 2} d_{g i} / y_{W}, 0\right), C_{W 1}=-0.01, C_{W 2}=0.05\end{aligned}$ \\
\hline \multirow{6}{*}{$k-\varepsilon$} & $\nabla \cdot\left(\rho_{l} \alpha_{l} k_{l} \mathbf{u}_{l}\right)=\nabla \cdot\left(\alpha_{l}\left(\mu_{l a m, l}+\left(\mu_{l l}+\mu_{t b}\right) / \sigma_{k}\right) \nabla k_{l}\right)$ \\
\hline & $+\alpha_{l}\left(G_{k, l}-\rho_{l} \varepsilon_{l}\right)+\alpha_{l} S_{k, l}$ \\
\hline & $\nabla \cdot\left(\rho_{l} \alpha_{l} \varepsilon_{l} \mathbf{u}_{l}\right)=\nabla \cdot\left(\alpha_{l}\left(\mu_{\text {lam, }, l}+\left(\mu_{t l}+\mu_{t b}\right) / \sigma_{\varepsilon}\right) \nabla \varepsilon_{l}\right)$ \\
\hline & $+\alpha_{l} \frac{\varepsilon_{l}}{k_{l}}\left(C_{\varepsilon 1} G_{k, l}-C_{\varepsilon 2} \rho_{l} \varepsilon_{l}\right)+\alpha_{l} S_{\varepsilon, l}$ \\
\hline & $\mu_{e f f, l}=\mu_{\text {lam }, l}+\mu_{t l}, \mu_{e f f, g i}=\rho_{g} / \rho_{l} \mu_{e f f, l}$ \\
\hline & $C_{\mu}=0.09 ; \sigma_{k}=1.00 ; \sigma_{\varepsilon}=1.3 ; C_{\varepsilon 1}=1.44, C_{\varepsilon 2}=1.92$ \\
\hline
\end{tabular}

\section{B. Mass Transfer Model}

Mass transfer rate between gas and liquid phase is an important factor in multiphase reactor performance. Interfacial mass transfer is usually expressed by volumetric mass transfer coefficient $k_{L} a$. Four different categories of mass transfer models have been reported in [13]. These are (1) phenomenological correlations and/or models; (2) spatial models; (3) time models and (4) combined film-penetration models. Huang et al. [13] compared several typical mass transfer models for one ALR and recommended the one time model proposed earlier by Cocke et al. [23] based on the penetration theory, as shown in (6).

$$
k_{L} a=12 \alpha_{g} / d_{b} \sqrt{D_{L} U_{s l i p} / \pi d_{b}}
$$

Equations (7) and (8) in the current study were employed to calculate the $k_{L} a$ between the liquid and each bubble phase, respectively. The overall $k_{L} a$, the sum of $\left(k_{L} a\right)_{\mathrm{g} 1}$ (large bubble size class) and $\left(k_{L} a\right)_{\mathrm{g} 2}$ ( small bubble size class), was validated against the experimental results.

$$
\left(k_{L} a\right)_{g 1}=12 \alpha_{g 1} / d_{g 1} \sqrt{D_{L} U_{s l i p, g 1} / \pi d_{g 1}}
$$

$$
\left(k_{L} a\right)_{g 2}=12 \alpha_{g 2} / d_{g 2} \sqrt{D_{L} U_{s l i p, g 2} / \pi d_{g 2}}
$$

\section{Numerical Details}

To reduce computational expense, one quarter of the 3-dimensional AR_ALR was taken as the computational domain. The configuration of the AR_ALR was generated according to the experimental equipment. The velocity inlet boundary was applied to the upper face of the gas distributor, where the gas inlet velocity and its volume fraction were specified according to the experiments. On the top domain surface, pressure outlet boundary condition was set. Symmetry boundaries were used for the two symmetrical surfaces of the quarter of the AR_ALR due to computational economics. The other boundary conditions were a standard non-slip condition for the liquid and gas phases on all the reactor walls.

3D steady state simulations were carried out with the commercial software ANSYS Fluent 14.5. For all the simulations, the phase-coupled SIMPLE algorithm was used for the solution of the pressure-velocity coupling. The second order upwind scheme was used for the momentum, turbulence kinetic energy and dissipation rate equations and the first-order scheme for the volume fraction equation. The residual convergence criterion for all the variables was set to $10^{-4}$. The mass balance of bubble phases and the volume-weighted average gas holdup for each bubble phase were additionally used to examine the convergence for all simulations.

\section{RESULT AND DISCUSSION}

\section{A. Mesh Independence}

The influence of the mesh size on the numerical solutions was examined with one coarse mesh case and another finer mesh. The coarse mesh had 43,824 hexahedron elements with the maximum edge size of $5 \mathrm{~mm}$. The number of the cells of the fined one was 400,896 with the maximum edge size of 2.5 $\mathrm{mm}$. The simulations were performed for both cases at gas superficial velocity $U_{g} 1.18 \mathrm{~cm} / \mathrm{s}$.

The relative discrepancy between the coarse and the finer mesh cases is $1.58 \%$ for the overall gas holdup and $0.81 \%$ for the $k_{L} a$. Fig. 2 shows the radial profile of the axial liquid velocity for both cases, where the difference is around $10 \%$. It can be seen that the coarse mesh is sufficient to obtain mesh independent solution. Therefore, it was used to conduct all the subsequent simulations.

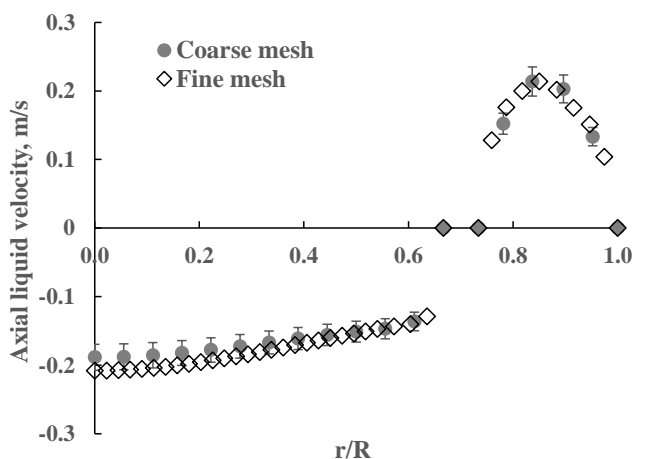

Fig. 2. Influence of mesh size on radial profile of axial liquid velocity. 


\section{B. Simulation and Validation of the Lab-Scale AR_ALR}

The simulated overall gas holdup agrees well with the experimental results over the range of the studied $U_{g}$, as shown in Fig. 3. The overall gas holdup increases with the increase of $U_{g}$.

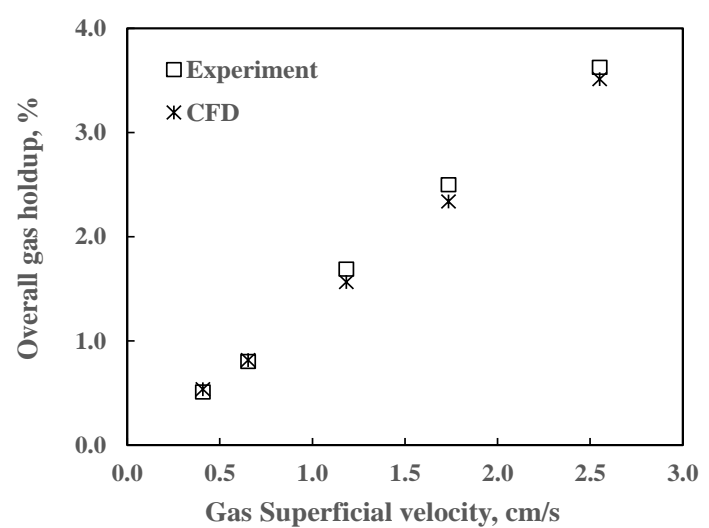

Fig. 3. Overall gas holdup at different $U_{g}$ : square-experiments; star-CFD.

Three flow regimes can be distinguished in ALRs depending how far the gas bubbles reach in the reactor. These are the "no gas entrainment" regime (regime I), "gas entrainment, but no recirculation" regime (regime II) and "complete gas recirculation" regime (regime III). As shown in Fig. 4 (a), (b) and (c), all the three flow regimes, which were also observed in the experiments, were captured with the developed model at different gas superficial velocities.

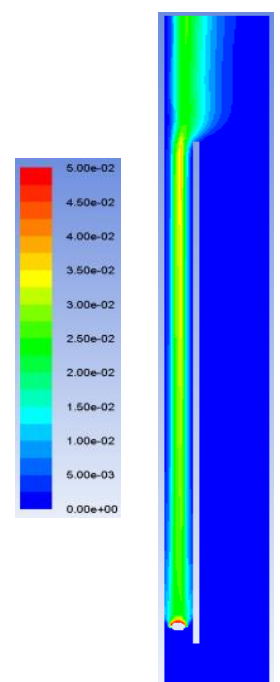

(a)

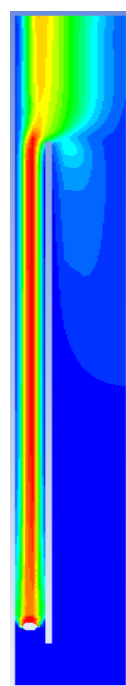

(b)

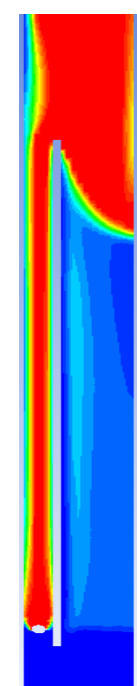

(c)
Fig. 4. Gas holdup profiles for three regimes: (a) $U_{g}=0.65 \mathrm{~cm} / \mathrm{s}$ (b) $U_{g}=1.18 \mathrm{~cm} / \mathrm{s}$ (c) $U_{g}=2.55 \mathrm{~cm} / \mathrm{s}$.

The volumetric mass transfer coefficient was validated against the experimental results under different $U_{g}$, as shown in Fig. 5. In overall, good agreement was obtained between the simulations and experiments although some discrepancy can be seen at $U_{g}=1.18 \mathrm{~cm} / \mathrm{s}$. This is probably caused by the more complex hydrodynamic characteristics of the flow at the transition from homogeneous to heterogeneous flow.

The local volumetric mass transfer coefficient from simulations is shown in Fig. 6 for the three different flow regimes. The maximum volumetric mass transfer coefficient appears at the inlet of the downcomer due to substantial accumulation of bubbles. It can be seen that the radial profile of $k_{L} a$ is 'core-peaking' in the riser and 'wall-peaking' in the downcomer (except for the case (a) of 'no bubble entrained into the downcomer flow regime'), which is in accordance with the gas holdup profile also. Only small bubbles can be entrained further into the downcomer. These small bubbles are located close to the wall of the downcomer. These results suggest that the developed three-phase Eulerian model can be used to accurately predict the hydrodynamics and mass transfer of the studied AR_ALR.

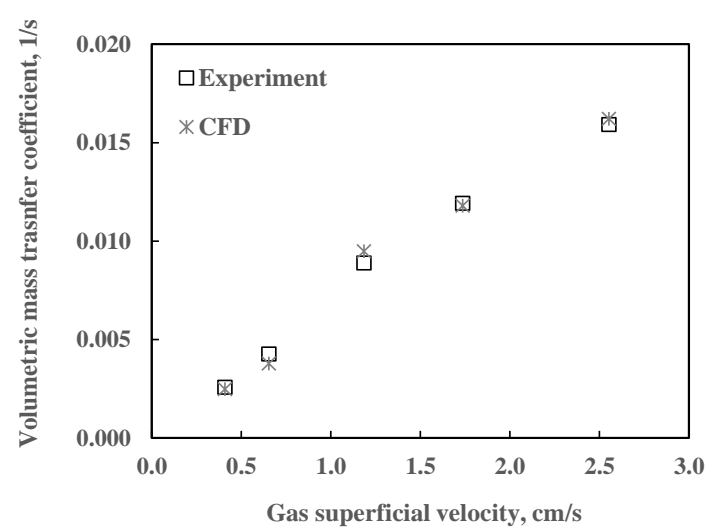

Fig. 5. Mass transfer at different $U_{g}$ : square-experiments; star-CFD.

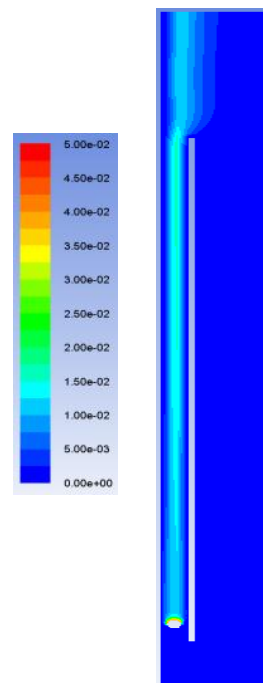

(a)

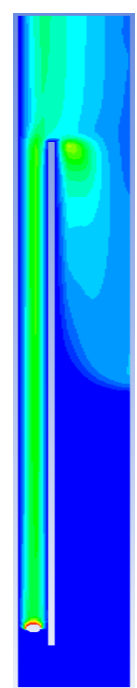

(b)

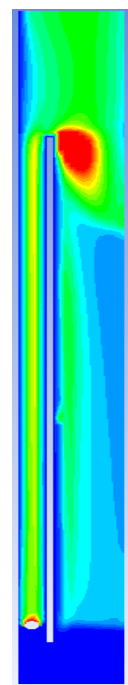

(c)
Fig. 6. Mass transfer profile for three regimes: (a) $U_{g}=0.65 \mathrm{~cm} / \mathrm{s}$ (b) $U_{g}=1.18 \mathrm{~cm} / \mathrm{s}$ (c) $U_{g}=2.55 \mathrm{~cm} / \mathrm{s}$.

\section{The Scale Effect Simulated by CFD}

The effect of reactor scale on the hydrodynamics and mass transfer of AR_ALR was investigated with CFD simulations. 3-D steady-state simulation was performed for an AR_ALR with a height of $4.5 \mathrm{~m}$. The ratio of the cross-sectional area of the riser to that of the downcomer was maintained the same as in the laboratory AR_ALR. The dimension of the computational domain for the larger AR_ALR is shown in Fig. 7. The number of the elements was 773,652 with the maximum edge of $5 \mathrm{~mm}$.

Fig. 8 shows the simulated overall gas holdup in the AR_ALRs with different scales and the comparison with the experiments. It can be seen that the overall gas holdup simulated with the larger scale AR_ALR is slightly higher than that with the laboratory scale. This is probably because much more bubbles can be entrained into the downcomer due 
to increasing liquid circulation. As pointed out by van Baten et al. [24], the friction losses of liquid phase encountered in larger scale reactor are reduced and therefore liquid circulation velocity increases. In order to validate the developed CFD model, further simulations with the larger scale reactor were performed on two more high gas superficial velocities and compared with the experimental data from [25]. As shown in Fig. 8, somewhat higher simulated gas holdup is, however, obtained probably due to absence of the enlarged gas separator part in the simulated AR_ALR.

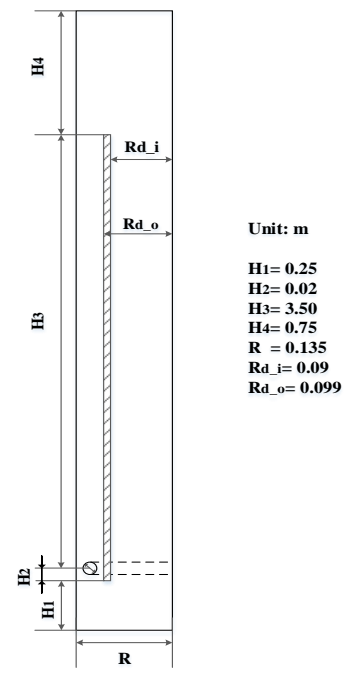

Fig. 7. Dimension of the scale-up AR_ALR.

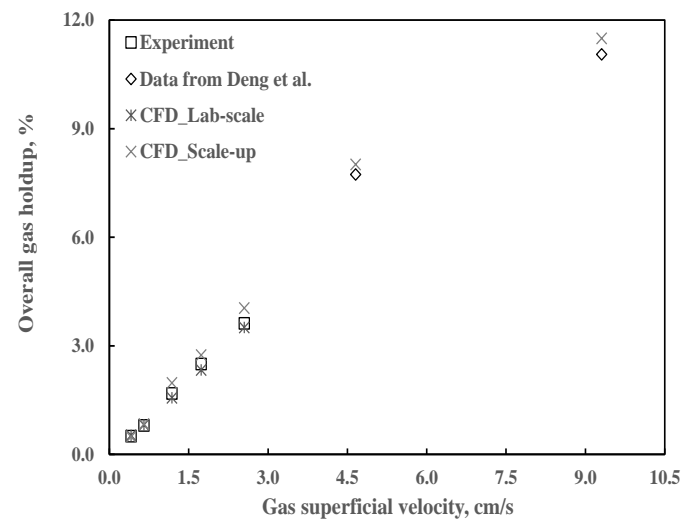

Fig. 8. Effect of reactor scale on overall gas holdup: square-experiments; diamond-from [25]; star-CFD with laboratory scale AR_ALR; cross-scale-up AR_ALR.

The cross-sectional area averaged liquid velocity in riser and downcomer obtained from simulation, are presented in Fig. 9 for the AR_ALRs with different scales. The average liquid velocities in the riser and downcomer increase with the increasing of gas superficial velocity. The increasing trend is significant at low $U_{g}$ but negligible at high $U_{g}$. The average liquid velocities are much higher in the large scale AR_ALR than in the lab-scale reactor. The average liquid velocity is high in the large-scale AR_ALR mostly because of the reduction in frictional resistance compared to the lab-scale. This also accounts for the effect of the reactor scale on the gas holdup, as shown before.

In Fig. 10, the volumetric mass transfer coefficients obtained in simulations and experiments are compared in the two reactor scales. The simulated results with the larger scale reactor are higher than that of the laboratory scale reactor, which is in accordance with the predicted gas holdup.
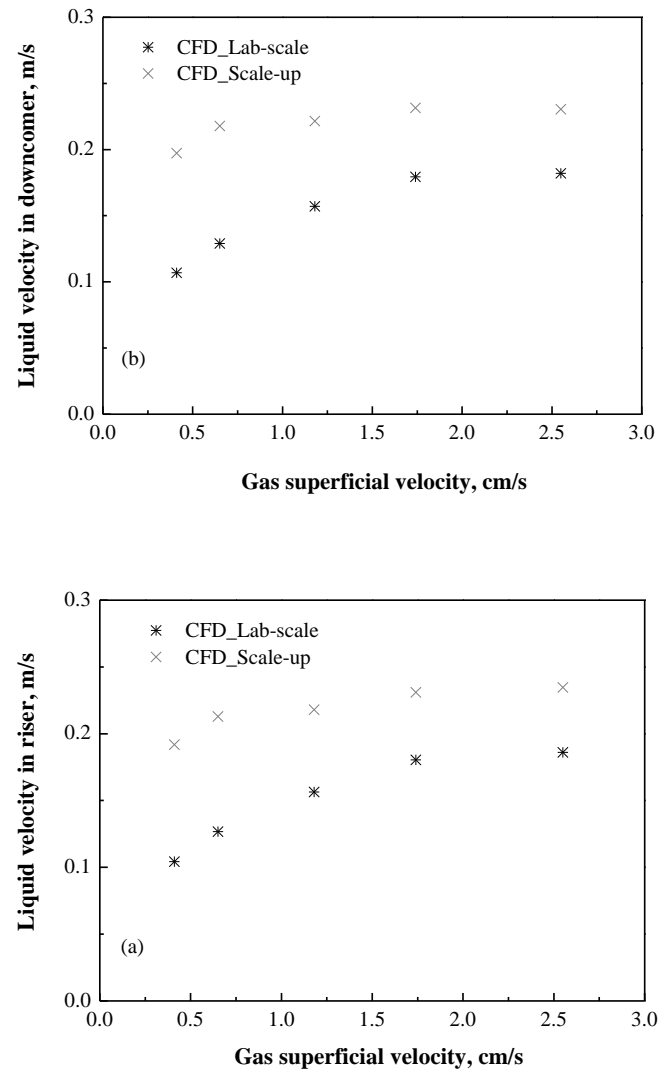

Fig. 9. Cross-sectional area averaged liquid velocity at the half of reactor height: (a) in riser, (b) in downcomer.

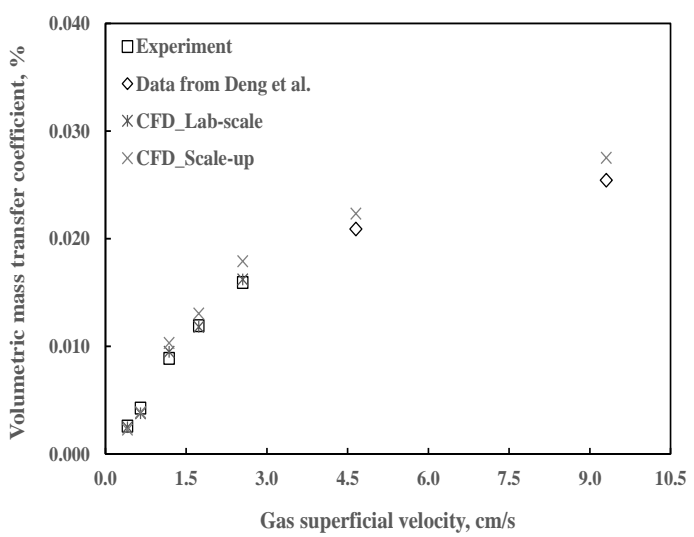

Fig. 10. Effect of reactor scale on volumetric mass transfer coefficient: square-experiments; diamond-from [23]; star-CFD with laboratory scale AR_ALR; cross-scale-up AR_ALR.

\section{CONCLUSION}

Hydrodynamic characteristics and mass transfer performance of the annulus-rising airlift reactor were investigated with experimental and CFD simulation methods. The effects of superficial gas velocity and reactor scale are presented and compared with our experimental results and those from literature.

An Eulerian model with two bubble phases was developed for simulating the AR_ALR. Good agreements on gas holdup and volumetric mass coefficient were obtained over the range of the studied gas superficial velocities. The three flow regimes observed in experiments in AR_ALR are also captured by the developed model. The effect of the reactor scale on average liquid velocities in AR_ALR is presented 
and it agrees well with results from van Baten et al. According to the comparison of experiments and simulations, the gas holdup and the volumetric mass transfer coefficients can be predicted well at different scales and gas superficial velocities using the developed Eulerian model with the proposed momentum terms.

\section{REFERENCES}

[1] M. Y. Chisti and M. Moo-Young, "Airlift reactors: Characteristics, applications and design considerations," Chem. Eng. Comm., vol. 60, pp. 195-242, 1987

[2] R. Bannari, A. Bannari, P. Vermette, and P. Proulx, "A model for cellulase production from Trichoderma reesei in an airlift reactor," Biotech. Bioeng., vol. 109, pp. 2025-2023, 2012.

[3] M. Y. Chisti, Airlift Bioreactors, London: Elsevier, 1989, pp. 8-9.

[4] C. C. Fu, L. S. Fan, and W. T. Wu, "Flow regime transitions in an inter-loop airlift reactor," Chem. Eng. Tech., vol. 30, pp. 1077-1082, 2007.

[5] L. C. Shing and H. S. Jye, "Local hydrodynamic properties of gas phase in an internal-loop airlift reactor," Chem. Eng. J., vol. 91, pp. 3-22, 2003.

[6] A. Fadavi and Y. Chisti, "Gas holdup and mixing characteristics of a novel forced circulation loop reactor," Chem. Eng. J., vol. 131, pp. 105-111, 2007

[7] H. P. Luo and M. H. Al-Dahhan, "Local characteristics of hydrodynamics in draft tube airlift bioreactor," Chem. Eng. Sci., vol. 63, pp. 3057-3068, 2008.

[8] P. M. Kilonzo, A. Margaritis, M. A. Bergougnou, J. T. Yu, and Q. Ye, "Effects of geometrical design on hydrodynamic and mass transfer characteristics of a rectangular-column airlift bioreactor," Biochem. Eng. J., vol. 34, pp. 279-288, 2007.

[9] Q. S. Huang, C. Yang, G. Z. Yu, and Z. S. Mao, "3-D simulations of an internal airlift loop reactor using a steady two-fluid model," Chem. Eng. Tech., vol. 30, pp. 870-879, 2007.

[10] M. Šimčík, A. Mota, M. C. Ruzicka, A. Vicente, and J. Teixeira, “CFD simulation and experimental measurement of gas holdup and liquid interstitial velocity in internal loop airlift reactor," Chem. Eng. Sci., vol. 66, pp. 3268-3279, 2011.

[11] Q. S. Huang, C. Yang, G. Z. Yu, and Z. S. Mao, "Sensitivity study on modeling an internal airlift loop reactor using a steady 2D two-fluid model," Chem. Eng. Tech., vol. 31, pp. 1790-1798, 2008.

[12] A. Sokolichin and G. Eigenberger, "Gas-liquid flow in bubble columns and loop reactors. Part-I. Detailed modelling and numerical simulation," Chem. Eng. Sci., vol. 49, pp. 5735-5746, 1994.

[13] Q. S. Huang, C. Yang, G. Z. Yu, and Z. S. Mao, "CFD simulation of hydrodynamics and mass transfer in an internal airlift loop reactor using a steady two-fluid model," Chem. Eng. Sci., vol. 65, pp. 5527-5536, 2010.

[14] H. P. Luo and M. H. Al-Dahhan, "Verification and validation of CFD simulations for local flow dynamics in a draft tube airlift bioreactor," Chem. Eng. Sci., vol. 30, pp. 907-923, 2011.

[15] E. R. Gouveia, C. O. Hokka, and A. C. Badino-Jr, "The effects of geometry and operational conditions on gas holdup, liquid circulation and mass transfer in an airlift reactor," Brazil. J. of Chem. Eng., vol. 20 , pp. 363-374, 2003.

[16] S. L. Sun, C. J. Liu, W. S. Wei, and X. J. Bao, "Hydrodynamics of an annulus airlift reactor,” Powder. Tech., vol. 162, pp. 201-207, 2006.

[17] K. Koide, K. Kurematsu, S. Iwamoto, Y. Iwata, and K. Horibe, "Gas holdup and volumetric liquid-phase mass transfer coefficient in bubble column with draught tube and with gas dispersion into annulus," $J$. Chem. Eng. Jap., vol. 16, pp. 407-413, 1983.

[18] K. Koide, K. Kurematsu, S. Iwamoto, Y. Iwata, and K. Horibe, "Gas holdup and volumetric liquid-phase mass transfer coefficient in bubble column with draught tube and with gas dispersion into tube," J. Chem. Eng. Jap., vol. 16, pp. 413-419, 1983.
[19] P. R. Lennartsson, C. Niklasson, and M. J. Taherzadeh, "A pilot study on lignocellulose to ethanol and fish feed using NMMO pretreatment and cultivation with zygomycetes in an air-lift reactor," Bioresour. Tech., vol. 102, pp. 4425-4432, 2011.

[20] H. Eloranta, M. Honkanen, and K. Marjanen, PORA-Object Recognition and Analysis Software 1.0 Users Manual, Version 1.0/9.9.2008, (C) Pixact Ltd.,.

[21] C. O. Vandu and R. Krishna, "Volumetric mass transfer coefficient in slurry bubble columns operating in the churn-turbulent flow regime," Chem. Eng. Process., vol. 43, pp. 987-995, 2004.

[22] H. M. Letzel, J. C. Schouten, R. Krishna, and C. M. van den Bleek, "Gas holdup and mass transfer in bubble column reactors operated at elevated pressure," Chem. Eng. Sci., vol. 54, pp. 2237-2246, 1999.

[23] A. Cockx., Z. D. Quang, J. M. Audic, A. Liné, and M. Roustan, "Global and local mass transfer coefficients in the waste water treatment process by computational fluid dynamics," Chem. Eng. Process., vol. 40, pp. 187-194, 2001.

[24] J.M. van Baten, J. Ellenberger, and R. Krishna, "Hydrodynamics of internal air-lift reactors: experiments versus CFD simulations," Chem. Eng. Process., vol. 42, pp. 733-742, 2003.

[25] Z. H. Deng, T. F. Wang, N. Zhang, and Z. W. Wang, "Gas holdup, bubble behavior and mass transfer in a $5 \mathrm{~m}$ high internal-loop airlift reactor with non-Newtonian fluid," Chem. Eng. J., vol. 160, pp. 729-737, 2010.

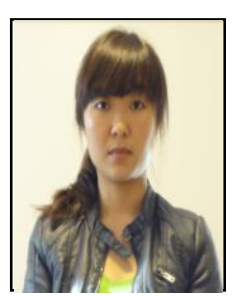

Mei Han is a PhD student at Lappeenranta University of Technology (LUT) in Finland. Her current research topic is fluid dynamic in chemical engineering and multiphase reactor design and development in the laboratory of Product and Process Development at LUT.

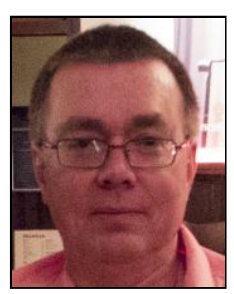

Arto Laari is a research scientist at Lappeenranta University of Technology (LUT). He received his $\mathrm{PhD}$ (2005) and the title of Docent (2010) from LUT in the field of product and process development. He has been working as an associate professor in the same department in 2010-2014. His current scientific interests are in the development of sustainable metal leaching processes and in the storage and transformation of renewable energy.

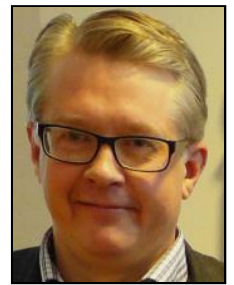

Tuomas Koiranen is a professor at Lappeenranta University of Technology (LUT). He received his $\mathrm{PhD}$ (1998) in Helsinki University of Technology, and the title of Docent (2004) from Lappeenranta University of Technology. After having 12 years industrial experience in pharmaceutical R\&D as a research scientist he started the professorship at Lappeenranta University of Technology in 2013. His current scientific and teaching interests are fluid dynamics in chemical engineering applications, liquid droplet behavior in reactive flows, process development and intensified processes. 